\title{
Equipment Reports
}

Hwan Joo MD FRCPC, Keith Rose MD FRCPC

\section{Fastrach - a new intubating laryngeal mask airway: successful use in patients with difficult airways}

Purpose: The Laryngeal Mask Airway - Fastrach ${ }^{T M}$ (Fastrach) is a new modified laryngeal mask with the capability for guided tracheal intubation while maintaining ventilation. We report the use of this device in patients with proven difficult airways, following induction of general anaesthesia.

Clinical features: After induction of general anaesthesia, having failed tracheal intubation with conventional laryngoscopy, the first patient's trachea was intubated via the Fastrach with fibreoptic guidance. In the second and third patients, who had documented histories of difficult tracheal intubation, tracheal intubation was performed electively with the Fastrach following induction of inhalational anaesthesia with spontaneous respiration.

Conclusion: The Fastrach is an option in the management of the airway following failed tracheal intubation or for elective tracheal intubation in patients with anatomically difficult airways.

Objectif : Le masque laryngé - Fastrach ${ }^{\circledR}$ est un nouveau masque laryngé modifié qui permet l'intubation trachéale guidée tout en maintenant la ventilation. Nous rapportons son usage après l'induction de l'anesthésie, chez des patients présentant des voies aériennes difficiles connues.

Aspects cliniques : Après induction de l'anesthésie et après échec d'intubation avec la laryngoscopie conventionnelle, le premier patient a été intubé avec fibroscopie via le Fastrach. Chez les deux patients suivants, qui présentaient une histoire d'intubation difficile, l'intubation fut réalisée de façon élective à l'aide du Fastrach suite à une induction par inhalation de l'anesthésie avec maintien de la respiration spontanée.

Conclusion : Le Fastrach représente une option dans la prise en charge des voies aériennes suite à une intubation impossible ou pour l'intubation trachéale élective des patients présentant des difficultés anatomiques.

From the Department of Anaesthesia, St. Michael's Hospital, University of Toronto.

Address correspondence to: Dr. Hwan Joo, Department of Anaesthesia, St. Michael's Hospital, 30 Bond Street, Toronto, Ontario M5B 1W8; Phonc: 416-864-5071; Fax: 416-864-6014.

Accepted for publication December 18, 1997. 
$\mathrm{T}$

$\mathrm{HE}$ following case reports describe the use of the Laryngeal Mask Airway - Fastrach ${ }^{\mathrm{TM}}$ (Fastrach, Figure 1), a new modified intubating laryngeal mask airway (LMA) specifically designed to allow guided tracheal intubation. We report its use in patients with proven difficult airways, following induction of general anaesthesia. In the first patient, having failed tracheal intubation with direct laryngoscopy, intubation was performed via the Fastrach. The second and third patients had their tracheas intubated electively with the Fastrach after previous histories of awake fibreoptic intubation for difficult airways.

\section{Subject and methods}

\section{Case \#I}

The patient was a 45-yr-old woman with a history of Graves' disease scheduled for ethmoidal orbital decompression. She had no history of gastro-oesophageal reflux. She was $155 \mathrm{~cm}$ tall and weighed $65 \mathrm{~kg}$. Physical examination revealed obvious Cushingoid features including moon facies, large tongue and a buffalo hump curvature over her upper thoracic spine. Her airway was recorded as equivocal by her attending anaesthetist. Airway was assessed as Mallampati class II with limited neck extension of $15^{\circ}$, thyromental distance of $5 \mathrm{~cm}$ and a mouth opening of $4 \mathrm{~cm}$.

Anaesthesia was induced with fentanyl, propofol and succinylcholine. After three attempts with conventional laryngoscopy the patient's trachea could not be intubated. Mask ventilation was moderately difficult due to her moon facies and body habitus but $\mathrm{CO}_{2}$ exchange was present. A size \#3 Fastrach was inserted. Ventilation was confirmed with $\mathrm{CO}_{2}$ exchange. A $5 \mathrm{~mm}$ Pentax fibreoptic bronchoscope was advanced through a lubricated $7 \mathrm{~mm}$, cuffed, uncut endotracheal tube (ETT), which was then inserted into the fastrach. After the vocal cords were identified, the fibreoptic bronchoscope was inserted into the trachea and the ETT was guided over the bronchoscope. After confirmation of successful tracheal intubation, rocuronium was used for paralysis. The Fastrach was removed to avoid obstruction of the surgical field. The circuit connector of the ETT was detached from the in situ $7 \mathrm{~mm}$ ETT and a new $6 \mathrm{~mm}$ was inserted into the lumen to make an elongated and functioning airway (Figure 2). The Fastrach was removed over this conduit. At no time was ventilation interrupted and the $\mathrm{SaO}_{2}$ remained $>95 \%$. Surgery was completed without further complications. After confirming a cuff leak, the ETT was removed. The patient experienced no residual airway problems except for a sore throat.

\section{Case \#2}

The patient was a 70-yr-old man, scheduled for knee manipulation. The patient had had six previous awake fibreoptic intubations after a history of difficult tracheal intubation. He was otherwise healthy. He weighed $85 \mathrm{~kg}$ and was $172 \mathrm{~cm}$ tall. His airway was assessed to be difficult with thyromental distance of $5 \mathrm{~cm}$, neck extension of $0^{\circ}$, Mallampati class III airway and mouth opening of $3 \mathrm{~cm}$.

The patient had developed an aversion to awake fibreoptic intubation and regional anaesthesia. Due to the possibility of femur fracture and subsequent blood loss associated with the procedure on this patient, tracheal intubation was deemed to be necessary. After detailed discussions with the patient, it was decided that the airway would be secured with the Fastrach and ETT.

Anaesthesia was induced with $1 \mathrm{mg} \cdot \mathrm{kg}^{-1}$ propofol, sevoflurane $8 \%$ and $\mathrm{N}_{2} \mathrm{O} 50 \%$. A size \#4 Fastrach was easily inserted at three minutes. The inhalational induc-

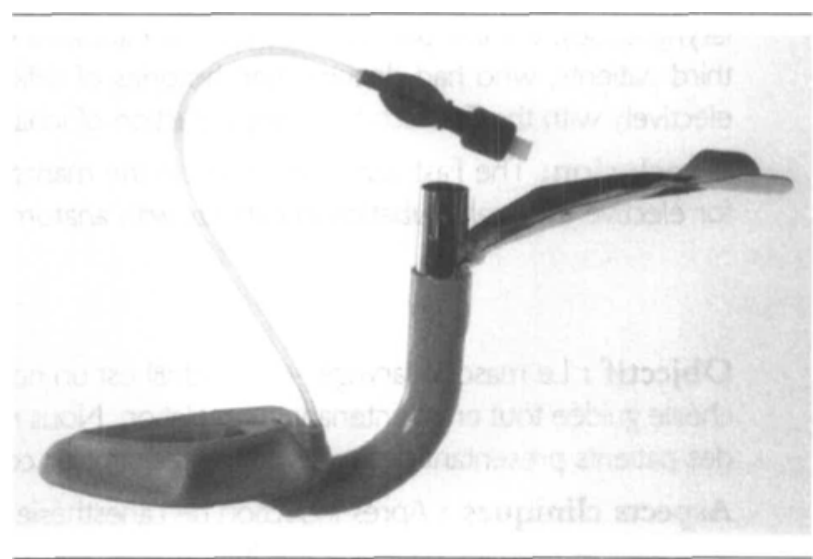

FIGURE 1 Size \#4 Laryngeal Mask Airway - Fastrach

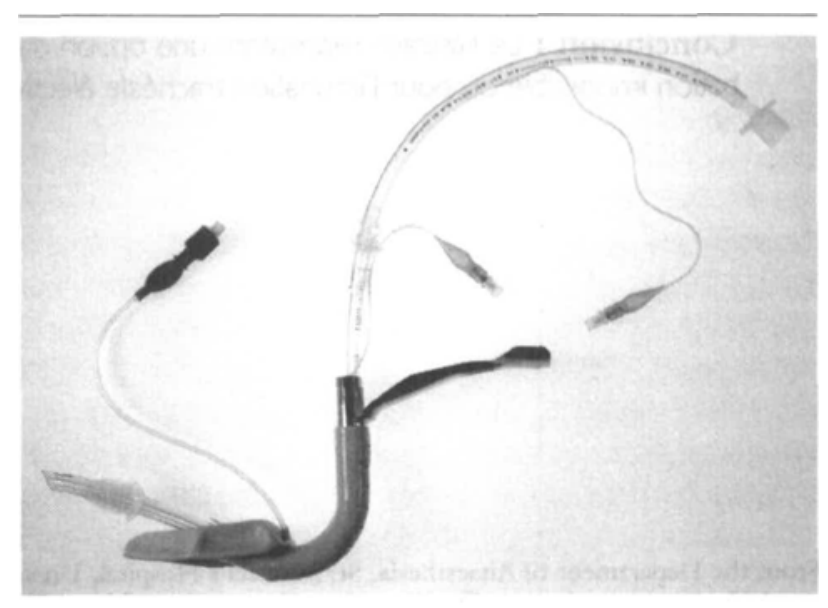

FIGURE $26 \mathrm{~mm}$ ETT connected to a $7 \mathrm{~mm}$ ETT (PVC Mallinkrodt Medical Intermediate $\mathrm{Hi}-\mathrm{LO}$ ) to make a functioning conduit for removal of the Fastrach 
tion with spontaneous respiration was continued for a further five minutes. Following topicalisation of the vocal cords with $100 \mathrm{mg}$ lidocaine, a $7 \mathrm{~mm} \mathrm{ETT}$, inserted through the Fastrach, was guided into the trachea with the help of a bronchoscope. Total time for tracheal intubation was three minutes as the airway was initially mistaken for the oesophagus. Only after the bronchoscope was passed through the false cords were the true cords seen. There were no episodes of desaturation and spontaneous respiration was maintained throughout. The Fastrach was removed using the method described in case \#1.

\section{Case \#3}

The third patient was a 60 -yr-old man scheduled for total knee arthroplasty. Due to a history of difficult tracheal intubation, the trachea had been previously intubated with awake fibreoptic bronchoscopy. For his last surgery, following induction of general anaesthesia, tracheal intubation was accomplished using a fibreoptic bronchoscope. However, tracheal intubation was moderately difficult due to his large tongue. $\mathrm{He}$ weighed $95 \mathrm{~kg}$ and was $180 \mathrm{~cm}$ tall. His airway was assessed to be difficult with a thyromental distance of $5 \mathrm{~cm}$, neck extension of $20^{\circ}$, a Mallampati class IV airway and a mouth opening of $4 \mathrm{~cm}$.

After three minutes of inhalational induction with sevoflurane $8 \%$ and $\mathrm{N}_{2} \mathrm{O} 50 \%$, a size \#5 Fastrach was inserted. A fibreroptic bronchoscope and a $7 \mathrm{~mm}$ ETT were inserted just past the distal opening of the Fastrach. After confirming full view of the vocal cords, the patient was paralysed with succinylcholine to control coughing. The $7 \mathrm{~mm}$ ETT was passed into the trachea with the fibreoptic bronchoscope just inside the ETT to confirm optimal placement. The ETT was inserted with a $180^{\circ}$ turn such that the concave curvature of the ETT faced down (backwards). The Fastrach was left in situ. There were no episodes of desaturation.

\section{Discussion}

The cases presented above show the successful use of the Fastrach for tracheal intubation in patients with difficult airways. In the first case the options following induction of general anaesthesia and the unexpected difficult laryngoscopy were to 1) attempt fibreoptic intubation under general anaesthesia, 2) awaken the patient, and 3) attempt tracheal intubation using the Fastrach with fibreoptic guidance. The first option was not optimal as ventilation was moderately difficult. The patient had considerable amounts of bleeding and secretions which would have made asleep fibreoptic intubation difficult. The third option was chosen after confirming easy ventilation with the Fastrach. The placement of the Fastrach kept the field of vision clear of blood and secretion, making identification of the airway easy. The one problem encountered was that the bronchoscope did not slide easily through the $7 \mathrm{~mm}$ ETT. This was attributed to insufficient lubrication.

In case \#3, to avoid coughing and bucking, the patient was electively paralysed with succinylcholine after confirming full view of the vocal cords with the bronchoscope. As ventilation had been established by the Fastrach, there were no contraindications to paralysis.

We used size \#3 and size \#4 Fastrach in the first two patients. However, Dr. A. Brain has since indicated (personal correspondence) that size \#4 and size \#5 Fastrachs are preferable for average sized women and men, respectively. The size \#3 Fastrach is appropriate only for small females.

The major advantage of using the Fastrach is the ability to maintain constant oxygenation and ventilation. As shown above, positive pressure or spontaneous ventilation is possible. There is indirect evidence that conventional LMA insertion is not compromised in patients with the difficult airways. ${ }^{1,2}$ As the Fastrach is a similar device, its effectiveness should be comparable. The Fastrach is shorter and wider than the conventional LMA. It allows for passage of a larger ETT (up to $8 \mathrm{~mm}$ ID) and safe, easy removal of the Fastrach after ETT insertion. After a failed tracheal intubation, the Fastrach protects the airway from oral secretions which could obstruct the view obtained through conventional fibreoptic endoscopy. The rigid anatomically curved airway tube allows single handed insertion without head or neck movement and without the need to insert a finger into the patient's mouth. The compressible mask-tube junction facilitates the passage of the Fastrach through an interdental gap as narrow as $2.0 \mathrm{~cm}$. Finally, the epiglottic elevating bar replaces the standard two bars on the LMA aperture, to increase success rates by lifting the epiglottis as the ETT is passed through the Fastrach.

The Split LMA, another modified intubating LMA, has been shown to have a near $100 \%$ success rate in experienced hands but is not commercially available. ${ }^{3}$ Hopefully, success rates will be similar with the Fastrach. The role for the Fastrach is still evolving. Eventually, it may prove to be an efficient and reliable instrument after failed tracheal intubation or for elective tracheal intubation in patients with anatomically difficult airways.

We attribute some of our success with tracheal intubation via the Fastrach to the direction of the ETT when it is advanced. When inserted backwards, as mentioned in case \#3 (Figure 3 usual direction compared with Figure 4 turned $180^{\circ}$ ), the ETT enters the trachea in a more anatomical direction. In all cases, we 


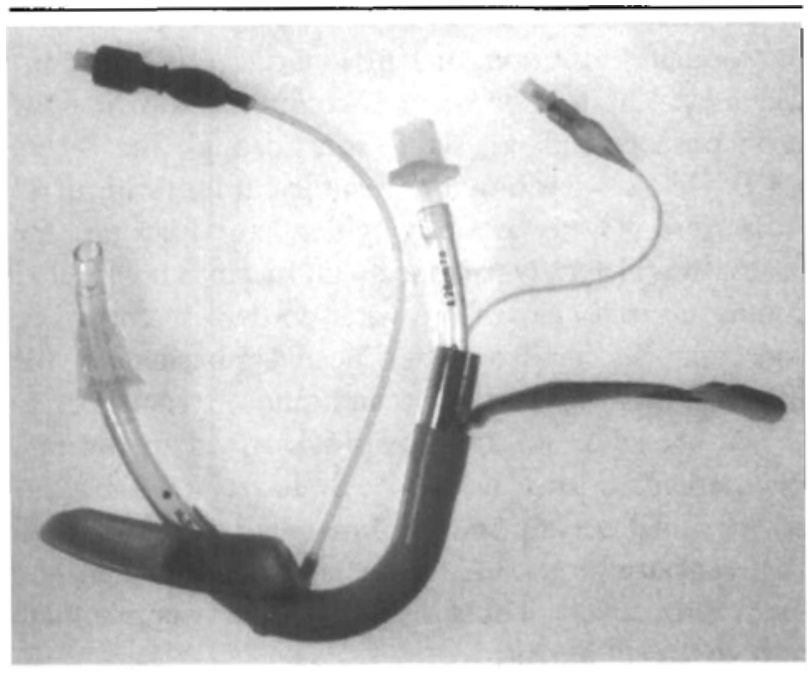

FIGURE $37 \mathrm{~mm}$ ETT inserted conventionally

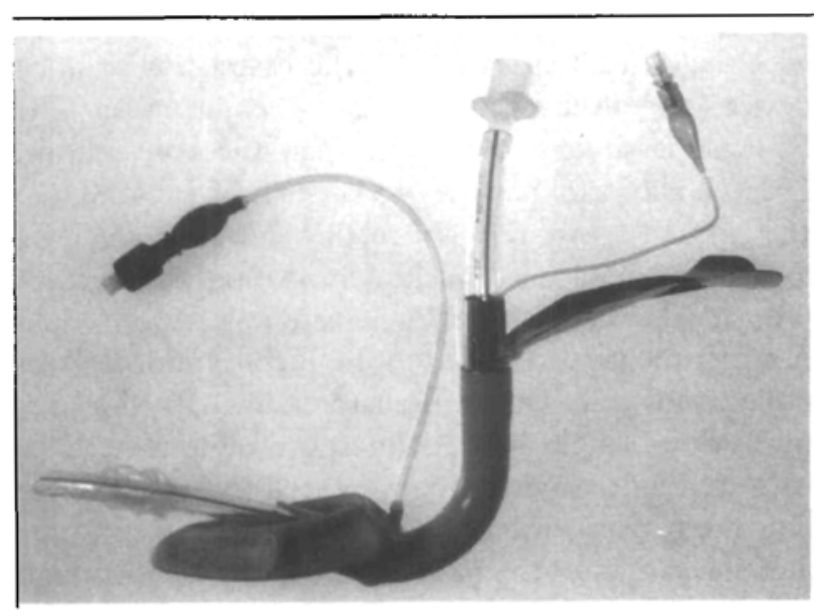

FIGURE $47 \mathrm{~mm}$ ETT inserted after turning $180^{\circ}$ with the concave curve facing down

have used a polyvinyl chloride (PVC), Mallinckrodt Medical Intermediate Hi-Lo ETT instead of the reinforced, flexible autoclaval be silicone ETT supplied by the distributer, Vitaid. Our reasons for the use of the PVC tubes are 1) they are cheaper (PVC ETT cost $<\$ 2$ vs silicone ETT $\sim \$ 50$-reusable), 2) they are single use and disposable, 3 ) in our hands, success rates for PVC ETTs inserted backwards were excellent and 4) PVC ETTs are more readily accessible.

In patients with normal airways, success rates with the Fastrach have been reported to be between $92-$ $100 \%{ }^{4-6}$ As the Fastrach is a new device, there are no sturdics on its effectiveness for patients with difficult airways. We encourage clinicians to familiarise themselves with its use on patients with normal airways before attempting to use the Fastrach for tracheal intubation in patients with difficult airways. All cases were performed by a single experienced operator. More studies will be needed to validate the safety and effectiveness of the Fastrach.

\section{References}

1 Mabiou P, Narchi P, Veyrac $P$, Germond $M$, Gory G, Bazin $G$. Is laryngeal mask easy to use in case of difficult intubation? Anesthesiology 1992; 77: A1228.

2 Brimacombe J. Analysis of 1500 laryngeal mask uses by one anaesthetist in adults undergoing routine anaesthesia. Anaesthesia 1996; 51: 76-80.

3 Darling $J R$, Keobane $M$, Murray JM. A split laryngeal mask as an aid to training in fiberoptic tracheal intubation. A comparison with the Berman II intubating airway. Anaesthesia 1993; 48: 1079-82.

4 Kapila $A, A d d y E V$, Verghese $C$, Brain $A I J$. Intubating laryngeal mask airway: a preliminary assessment of performance. (Abstract) Br J Anaesth 1995; 75: 228P-9.

5 Cros $A M$, Colombani $S$. Preliminary study of intubation with a new laryngeal mask for difficult intubation. Anesthesiology 1997; 87: A482.

6 Ferson DZ, Supkis DE, Rablfs $T F$, Jones $R L$. Evaluation of the intubating laryngeal mask as a primary airway device and a guide for blind endotracheal intubation. Anesthesiology 1997; 87: A485. 